\title{
Diabetes and urbanization in the Omani population: an analysis of national survey data Siba Al-Moosa1 ${ }^{1}$, Sara Allin*1, Nadia Jemiai ${ }^{1}$, Jawad Al-Lawati² and Elias Mossialos ${ }^{1}$
}

Address: ${ }^{T}$ The London School of Economics and Political Science, LSE Health and Social Care, UK and ${ }^{2}$ Ministry of Health, Oman Email: Siba Al-Moosa - sibalse@aol.com; Sara Allin* - s.m.allin@lse.ac.uk; Nadia Jemiai - n.jemiai@lse.ac.uk; Jawad AlLawati - jallawat@yahoo.com; Elias Mossialos - e.a.mossialos@lse.ac.uk

* Corresponding author

Published: 24 April 2006

Population Health Metrics2006, 4:5 doi:10.1 186/1478-7954-4-5
Received: 06 December 2005

Accepted: 24 April 2006

This article is available from: http://www.pophealthmetrics.com/content/4/1/5

(c) 2006AIMoosa et al; licensee BioMed Central Ltd.

This is an Open Access article distributed under the terms of the Creative Commons Attribution License (http://creativecommons.org/licenses/by/2.0), which permits unrestricted use, distribution, and reproduction in any medium, provided the original work is properly cited.

\begin{abstract}
Background: The prevalence of type 2 diabetes in Oman is high and appears to be rising. Rising rates of diabetes and associated risk factors have been observed in populations undergoing epidemiological transition and urbanization. A previous study in Oman indicated that urbandwellers were not significantly more likely to have diabetes. This study was undertaken to determine if a more accurate urban and rural categorization would reveal different findings.
\end{abstract}

Methods: This study included 7179 individuals aged 20 years or above who participated in a crosssectional interviewer-administered survey in Oman including blood and anthropomorphic tests. Multiple logistic regression analyses were conducted to analyze the factors associated with diabetes, first in the whole population and then stratified according to region.

Results: The prevalence of diabetes (fasting blood glucose $\geq 7 \mathrm{mmol} / \mathrm{l}$ ) in the capital region of Muscat was $17.7 \%$ compared to $10.5 \%$ in rural areas. The prevalence of self-reported diabetes was 4.3\%. Urban residence was significantly associated with diabetes (adjusted odds ratio $(O R)=1.7$, 95\% confidence interval (Cl): I.4-2.I), as was age (OR $=1.2,95 \% \mathrm{Cl}$ : I.I - I.2), obesity (abnormal waist circumference) $(\mathrm{OR}=1.8,95 \% \mathrm{Cl}$ : I.5-2.I), and systolic blood pressure (SBP) I20-I39 (OR $=1.4,95 \%$ Cl: I.04-I.8), SBP I40-I59 (OR = I.9, 95\% Cl: I.4-2.6), SBP $\geq 160$ (OR = I.7, 95\% Cl: I.2-2.5). Stratified analyses revealed higher education was associated with reduced likelihood of diabetes in rural areas $(\mathrm{OR}=0.6,95 \% \mathrm{Cl}: 0.4-0.9)$.

Conclusion: A high prevalence of diabetes, obesity, hypertension and high cholesterol exist in the Omani population, particularly among urban-dwellers and older individuals. It is vital to continue monitoring chronic disease in Oman and to direct public health policy towards preventing an epidemic.

\section{Background}

Epidemiological studies reveal rising rates of type 2 diabetes worldwide, notably in developing countries undergoing epidemiological transition from communicable to chronic diseases [1,2]. This has also been observed in certain populations that have undergone relatively rapid transition from rural to urban lifestyle [3-5]. Studies in low- and middle-income countries have identified that 
risk factors for chronic diseases are more prevalent in urban than rural areas [6-9].

Although the Sultanate of Oman has been successful in reducing communicable diseases and increasing life expectancy at birth to 76 years for women and 71 for men [10], rapid cultural changes and social advances since 1970 have led to the manifestation of a wide range of noncommunicable diseases [11]. The 2004 population is extremely young, with only $3 \%$ aged 60 years or older [10].

The fifth Health Development Plan in Oman (19962000) identified, for the first time, diabetes as a major concern and set specific goals to prevent further progression of the disease [12]. The National Diabetes Survey conducted in 1991 showed that $10 \%$ of the Omani population over the age of 20 years had diabetes mellitus, resulting in an estimated 80,000 people living with diabetes [13]. Also, a recent study of metabolic syndrome in an Omani city, Nizwa, reported a prevalence of high fasting glucose of $18 \%$ in 2001 [14].

A recent study conducted in Oman [11] identified that diabetes was associated with the classic risk factors [15], but not urbanization. The authors' definition of urbanization was based on each wilayate (district) being divided into two sections: the first section comprised the wilayates' centers representing the urban area and the second section comprised the villages or remote parts, which represent the rural areas [11]. According to this definition, $73.1 \%$ of the population resides in urban areas.

Consistent with this definition, the World Bank and UNDP also present high figures of urbanization in Oman. Specifically, in 2001 an estimated $76 \%$ of the population was considered urban [16], compared to $77 \%$ in 2002 [17].

However, other studies suggest a very different urbanrural distribution (e.g. 11\% urban in 1990 [18]; 10.6\% urban in 1990 and $15.1 \%$ in 2000 [19]). Similarly, we believe the only area in Oman that can be considered urban is the capital region of Muscat, constituting 21.7\% of the population in 2000 .

The population density (persons $/ \mathrm{km}^{2}$ ) in the region of Muscat is 162.1 , compared to 52.3 in the second most populated region (Al Batinah), with the remaining regions relatively sparsely populated (0.3-15.8 persons/ $\mathrm{km}^{2}$ ) [20]. In addition, about half of all commercial banks, vehicles on the road, electricity connections, and telephone lines in Oman are found in the capital region of Muscat, which can be seen as an indirect indication of urbanization [20]. Furthermore, health facilities are con- centrated in the capital region; about $30 \%$ of all hospital beds, and $40 \%$ of private health clinics are located in Muscat [20]. Moreover, the average occupancy rate of the Muscat hospitals is much higher than the other regions: $66 \%$ compared to an average of $46 \%$ across the remaining regions [20]. The only international airport in the country is located in Muscat; the same is true for the only government university. Finally, the presence of American companies further demonstrates the potentially different lifestyle among those living in Muscat; there are four Starbucks and four McDonalds restaurants in Oman, all of which reside in Muscat.

Socio-demographic characteristics of the urban and rural populations also differ significantly. Table 1 shows the age, sex and educational distribution of the populations in Muscat and the remaining regions. Overall, Muscat has a younger, better educated population with a slightly smaller average family size.

The objectives of the present study are twofold: to measure the prevalence of diabetes and associated coronary risk factors across demographic and socioeconomic descriptors; and to determine the significant factors associated with diabetes, in particular to examine whether urban residence as we have described above (i.e. living in the capital region) is independently associated with diabetes, adjusting for other risk factors and demographic factors.

\section{Methods}

\section{Study population and sampling method}

The sample for the 2000 National Health Survey was chosen so that it would represent the ten regions in the Sul-

Table I: Socio-demographic characteristics of urban (Muscat) and rural populations

\begin{tabular}{lll}
\hline & Urban (\%) & Rural (\%) \\
\hline Age & & \\
$20-29$ & 40.5 & 41.2 \\
$30-39$ & 24.3 & 20.6 \\
$40-49$ & 14.5 & 10.9 \\
$50-59$ & 10.7 & 13.9 \\
$\geq 60$ & 10.0 & 13.3 \\
Sex & & \\
Male & 48.8 & 50.3 \\
Female & 51.2 & 49.7 \\
Education level & & \\
Illiterate & 24.8 & 36.1 \\
Less than secondary & 37.5 & 41.8 \\
Secondary or above & 37.7 & 22.1 \\
Average family size & 7.3 & 8.0 \\
\hline
\end{tabular}

Note: Data are from the 2000 National Health Survey 
tanate. First, a multi-stage stratified probability-sampling design was used to randomly select a number of wilayates (districts) from each region, according to proportional allocation of population size in each region. There are 59 wilayates in Oman, of which 16 were chosen for the survey. Second, within the wilayates, enumeration areas (as defined by the 1993 census) were randomly selected. Third, within the enumeration areas, households were randomly selected. The present analysis considered the capital region of Muscat to be urban, and considered the remaining nine regions to be rural.

All subjects aged 20 and above in each of the chosen households were requested to participate in the survey. Out of the 2044 occupied households in the sample, 1968 were interviewed with a total of 17,574 subjects (96\%), of which 7179 were aged 20 or older. The response rate of subjects aged 20 or above was relatively high for all medical measurements: height, weight and blood pressure $(90 \%)$, waist measurement $(89 \%)$, hip measurement $(86 \%)$, fasting blood glucose $(81 \%)$ and serum cholesterol samples $(82 \%)$.

\section{Data collection}

A questionnaire developed by the Ministry of Health was administered by trained interviewers. The questionnaire included demographic background (age, sex, marital status, educational status, and working status) and selfreported diabetes mellitus, hypertension and smoking habits. The survey protocol also included measurements of blood pressure, weight, height, waist and hip circumference, taken by nurses according to WHO recommendations [21]. Blood samples of venous fasting blood glucose and serum cholesterol were also collected. Details of the sample collections are given elsewhere [22]. Fasting was ensured through visits by the interview teams to the houses on two consecutive days: on the first day, participants were requested to fast after dinner; on the second day the participants were visited in the morning, and blood samples were taken only for those individuals who confirmed they had fasted.

Diabetes was determined through adding the individuals with self-reported diabetes to those with a fasting blood glucose of $\geq 7.0 \mathrm{mmol} / \mathrm{l}$, following the WHO criteria for diagnosis of glucose intolerance [21].

\section{Data analysis}

Blood pressure was measured twice for each individual and mean systolic blood pressure (SBP) in $\mathrm{mmHg}$ was separated into four categories: <120; 120-139; 140-159; and $\geq 160$. Hypertension in this study was defined as SBP $\geq 140 \mathrm{mmHg}$. Cholesterol levels $(\mathrm{mmol} / \mathrm{L})$ were divided into quartiles $(<4.3 ; 4.3-5 ; 5.1-5.8$; and $>5.8)$; cholesterol $\geq 5 \mathrm{mmol} / \mathrm{L}$ was considered to be high.
Measures of obesity included waist circumference, body mass index [BMI; weight in kilograms divided by the square of the height in meters $\left.\left(\mathrm{kg} / \mathrm{m}^{2}\right)\right]$, and waist-to-hip ratio. Following WHO guidelines, waist circumference was considered to be abnormal $\geq 102 \mathrm{~cm}$ for men and $\geq$ $88 \mathrm{~cm}$ for women; and waist-to-hip ratio (WHR) was considered to be abnormal $>0.95 \mathrm{~cm}$ for men and $>0.85 \mathrm{~cm}$ for women. Respondents were classified as overweight if $\mathrm{BMI} \geq 25$ and $<30$ and obese if $\mathrm{BMI} \geq 30$.

The demographic variables include: age, grouped into 17 five-year age bands between 20 and 109 years; sex; and marital status, measured as married or not married (including divorced, separated, widowed or never married). Whether the individual smoked was also included. Level of education is separated into three groups: illiterate; less than secondary school; and secondary school and above. No other available measure of income or socioeconomic status was available in this survey.

Place of residence was used to categorize individuals into urban and rural. Those living in Muscat were considered to be urban-dwellers, while those residing in the rest of the country were considered to be living in rural areas.

The prevalence of diabetes, hypertension, high cholesterol, and obesity by region, demographic and educational status was measured. Then multiple logistic regression analyses were conducted to analyze the significant factors associated with the dependent variable, diabetes, first in the whole population and then stratified according to region. Independent variables were selected on the basis of the literature of diabetes risk factors [23]. Due to the high degree of colinearity between the three measures of obesity, only waist circumference was chosen for the regression models, as recommended by WHO. Most of the variables included within the models are categorical, thus dummy variables are created. Results are presented as crude and adjusted odds ratios with associated $95 \%$ confidence intervals. All analyses were conducted using Stata 8 ; $p$-value of $<0.05$ was considered significant.

\section{Results}

Table 2 presents the prevalence of diabetes, hypertension, high cholesterol and obesity across the identified independent variables. Among the population aged 20 or above, the overall prevalence of diabetes was $11.6 \%$ and varied according to urban or rural residence, age, marital status, educational level, smoking status, measures of obesity (BMI, WHR, waist circumference), cholesterol and SBP. The prevalence of hypertension (mean SBP $\geq 140$ $\mathrm{mmHg}$ ), and obesity (BMI $\geq 30$ ) among the adult population were $21.5 \%$ and $19.1 \%$ respectively. High cholesterol 
Table 2: Prevalence (\%) of diabetes, hypertension, high cholesterol, and obesity by urban residence and selected variables.

\begin{tabular}{|c|c|c|c|c|}
\hline & $\begin{array}{l}\text { Diabetes } \\
(\mathrm{n}=676 / 5840)\end{array}$ & $\begin{array}{l}\text { Hypertension } \\
(\mathrm{n}=1389 / 6464)\end{array}$ & $\begin{array}{l}\text { Cholesterol=5 } \\
(n=2974 / 5876)\end{array}$ & $\begin{array}{l}\text { BMI }=30 \\
(n=1224 / 6430)\end{array}$ \\
\hline Total & 11.6 & 21.5 & 50.6 & 19.1 \\
\hline \multicolumn{5}{|l|}{ Residence } \\
\hline Urban & 17.7 & 26.4 & 50.0 & 19.9 \\
\hline Rural & 10.5 & 20.2 & 50.7 & 18.8 \\
\hline \multicolumn{5}{|l|}{ Age } \\
\hline $20-29$ & 3.6 & 7.95 & 32.1 & 13.4 \\
\hline $30-39$ & 8.5 & 14.5 & 55.7 & 24.8 \\
\hline $40-49$ & 17.1 & 25.7 & 59.4 & 28.6 \\
\hline $50-59$ & 22.6 & 39.3 & 69.2 & 22.2 \\
\hline$\geq 60$ & 23.1 & 52.2 & 71.3 & 15.0 \\
\hline \multicolumn{5}{|l|}{ Sex } \\
\hline Male & 11.8 & 32.5 & 50.8 & 15.5 \\
\hline Female & 11.3 & 22.7 & 50.4 & 22.2 \\
\hline \multicolumn{5}{|l|}{ Marital status } \\
\hline Married & 13.2 & 22.8 & 55.8 & 21.6 \\
\hline Not married & 8.0 & 18.4 & 39.3 & 13.5 \\
\hline \multicolumn{5}{|l|}{ Education level } \\
\hline Illiterate & 17.1 & 34.7 & 62.1 & 19.8 \\
\hline Less than secondary & 10.2 & 16.9 & 48.6 & 20.1 \\
\hline Secondary or above & 5.4 & 9.9 & 36.8 & 16.1 \\
\hline \multicolumn{5}{|l|}{ Smoker } \\
\hline Yes & 12.2 & 25.2 & 50.3 & 14.5 \\
\hline No & 11.5 & 21.2 & 50.6 & 19.4 \\
\hline \multicolumn{5}{|l|}{ BMI $\left(\mathrm{kg} / \mathrm{m}^{2}\right)$} \\
\hline$<18.5$ & 6.9 & 14.7 & 36.4 & - \\
\hline $18.5-24.99$ & 8.1 & 18.5 & 44.8 & - \\
\hline $25-29.99$ & 14.7 & 22.6 & 58.0 & - \\
\hline$\geq 30$ & 16.5 & 29.7 & 58.9 & - \\
\hline \multicolumn{5}{|l|}{ WHR (cm) } \\
\hline Normal & 8.2 & 16.4 & 43.9 & 12.3 \\
\hline Abnormal (men >0.95; women >85) & 15.5 & 27.3 & 58.4 & 26.6 \\
\hline \multicolumn{5}{|l|}{ Waist circumference $(\mathrm{cm})$} \\
\hline Normal & 9.5 & 18.5 & 47.2 & 7.8 \\
\hline Abnormal $($ men $=102 ;$ women $=88)$ & 18.1 & 30.7 & 61.5 & 53.2 \\
\hline \multicolumn{5}{|l|}{ Cholesterol (mmol/L) } \\
\hline$<4.3$ & 5.5 & 13.2 & - & 12.8 \\
\hline $4.3-5$ & 8.0 & 18.5 & - & 18.2 \\
\hline $5-5.8$ & 12.6 & 22.8 & - & 19.8 \\
\hline$\geq 5.8$ & 17.8 & 32.9 & - & 23.5 \\
\hline \multicolumn{5}{|l|}{ SBP $(\mathbf{m m H g})$} \\
\hline$<120$ & 6.2 & - & 44.2 & 12.9 \\
\hline $120-139$ & 9.8 & - & 47.8 & 18.8 \\
\hline $140-159$ & 19.6 & - & 60.9 & 25.3 \\
\hline$\geq 160$ & 24.4 & - & 74.5 & 28.9 \\
\hline
\end{tabular}

Note: SBP is systolic blood pressure; BMI is body mass index; WHR is waist-to-hip ratio

( $\geq 5 \mathrm{mmol} / \mathrm{L}$ ) affects more than half of the adult Omani population.

Furthermore, diabetes affects a much greater proportion of the urban population (17.7\%) than rural $(10.5 \%)$. Similarly, hypertension is more common in urban $(26.4 \%)$ than in rural areas $(20.2 \%)$. The difference in prevalence of obesity in urban areas and rural areas appears to be less significant, as with the prevalence of high cholesterol. A gradient in unstandardized diabetes prevalence was also observed with education suggesting that the higher educated individuals were less likely to have diabetes than the illiterate or less educated groups.

Table 3 shows the variables that are significantly associated with diabetes, ceteris paribus. Of the 7179 respondents aged 20 or over, 5847 individuals were included in the analysis due to missing data for one or more of the variables. Individuals living in the urban capital region were almost twice as likely to have diabetes as those living in the rural areas. Furthermore, advanced age, being 
Table 3: Significant factors associated with diabetes $(p<0.05)$

\begin{tabular}{|c|c|c|c|c|}
\hline & No diabetes $(n=5164)$ & Diabetes $(n=676)$ & Crude OR $(95 \% \mathrm{Cl})$ & Adjusted OR $*(95 \% \mathrm{Cl})$ \\
\hline & n (\%) & n (\%) & & \\
\hline \multicolumn{5}{|l|}{ Residence } \\
\hline Urban & $74 \mid(82.3)$ & $159(17.7)$ & $1.8(1.5-2.2)$ & $1.7(1.4-2.1)$ \\
\hline Rural & $4430(89.6)$ & $517(10.5)$ & - & - \\
\hline Age $^{ \pm}$ & & & $1.2(1.2-1.3)$ & $1.2(1.1-1.2)$ \\
\hline \multicolumn{5}{|c|}{ Marital status } \\
\hline Not married & $|72|(92.0)$ & $149(8.0)$ & - & - \\
\hline Married & $3431(86.8)$ & $523(13.2)$ & $1.8(1.5-2.1)$ & $1.4(1.1-1.7)$ \\
\hline \multicolumn{5}{|c|}{ Waist circumference $(\mathrm{cm})$} \\
\hline Normal & $4023(90.5)$ & $422(9.5)$ & - & - \\
\hline Abnormal & $1148(81.9)$ & $254(18.1)$ & $2.1(1.8-2.5)$ & $1.8(1.5-2.1)$ \\
\hline \multicolumn{5}{|c|}{ SBP (mmHg) } \\
\hline$<120$ & $|23|(93.8)$ & $81(6.2)$ & - & - \\
\hline $120-139$ & $287 \mid(90.2)$ & $311(9.8)$ & $1.6(1.3-2.1)$ & $1.4(1.04-1.8)$ \\
\hline $140-159$ & $751(80.4)$ & $183(19.6)$ & $3.7(2.8-4.9)$ & $1.9(1.4-2.6)$ \\
\hline$\geq 160$ & $264(75.6)$ & $85(24.4)$ & $4.9(3.5-6.8)$ & $1.7(1.2-2.5)$ \\
\hline
\end{tabular}

Note: SBP is systolic blood pressure. * Odds ratios adjusted for all variables included in the model. ${ }^{ \pm}$Age is grouped into 17 five-year age bands between 20 and 109 years. Therefore for every five year increase in age, there is a 1.2 greater odds of having diabetes.

married, and abnormal waist circumference also increased the odds of diabetes.

A strong gradient was apparent with SBP: compared to SB $\mathrm{p}<120 \mathrm{mmHg}$ the adjusted OR for diabetes increased from 1.4 (SBP: $120-139 \mathrm{mmHg}$ ) to 1.9 (SBP: $140-159$ $\mathrm{mmHg}$ ) and decreased to $1.7(\mathrm{SBP}=160 \mathrm{mmHg})$. The lack of a linear relationship between SBP and diabetes is likely a result of the small sample of individuals in the highest SBP group.

After controlling for the other factors, education was not significantly associated with diabetes, except with stratified analyses by region (see Table 4). These stratified analyses revealed that higher educated individuals, particularly in rural areas, were less likely than illiterate individuals to have diabetes.

\section{Discussion}

As expected with the use of a more accurate categorization of urban and rural areas in Oman, residence was found to be a significant independent factor for diabetes similar to other epidemiological studies $[24,25]$. Because the impact of urban residence on likelihood of diabetes persisted after adjusting for demographic and educational variables, there are some unobserved unique features of urban populations that increase their risk of diabetes. These variables are likely to relate to lifestyle factors or perhaps to characteristics of employment.

Possibly explaining the higher prevalence of diabetes in the urban area is the change in dietary patterns, physical activity patterns and lifestyle associated with urbanization (which has been taking place to a large extent in the past
30 years, as witnessed by the increasing migration of Omanis to Muscat) [26,27]. Moreover, in the past 30 years Oman experienced rapid socioeconomic developments that were associated with a sharp rise in car ownership, an increase in consumption of high fat caloric-dense food, refined sugar and salt, and increased rates of smoking [28].

It is unlikely that the elevated rate of diabetes in the capital region is due to lack of awareness or diagnosis among rural-dwellers, since the same haematological criteria to determine diabetes were used for all individuals. Because of the lack of available information on income, lifestyle factors such as diet and exercise, household expenditure, or socioeconomic status, it is not possible to test whether these factors may help explain the relationship between urbanization and diabetes.

The results of this study indicate that hypertension is significantly associated with diabetes, particularly among urban-dwellers. Also, the prevalence of hypertension is higher in the capital region than the rural areas. These findings are consistent with previous studies [8,13,29-32], and indicate that individuals in the capital region are at higher risk for developing both diabetes and cardiovascular disease, due to elevated prevalence of coronary risk factors, than those in rural regions of Oman.

Almost one-fifth of the adult Omani population are obese. The past decade has witnessed an increase in the rate of obesity and overweight among Omani men, while a declining trend has been observed among Omani women [28]. In the urban area, this high prevalence could 
Table 4: Significant factors associated with diabetes in urban and rural areas $(p<0.05)$ or $(p<0.10)^{*}$

\begin{tabular}{|c|c|c|c|c|}
\hline & $\begin{array}{l}\text { Diabetes in urban areas } \\
(n=159)\end{array}$ & & $\begin{array}{l}\text { Diabetes in rural areas } \\
(n=517)\end{array}$ & \\
\hline & n (\%) & Adjusted OR $(95 \% \mathrm{Cl})$ & n (\%) & Adjusted OR $(95 \% \mathrm{Cl})$ \\
\hline Age $^{ \pm}$ & - & $1.2(1.1-1.2)$ & & $1.2(1.17-1.24)$ \\
\hline \multicolumn{5}{|l|}{ Marital status } \\
\hline Not married & $35(11.1)$ & - & II4 (7.3) & - \\
\hline Married & $120(20.7)$ & $1.6(1.0-2.3)$ & $403(11.9)$ & I.3 (I.0-I.7) \\
\hline \multicolumn{5}{|l|}{ Educational level } \\
\hline Illiterate & $68(28.0)$ & - & $323(15.6)$ & - \\
\hline Less than secondary & $43(12.9)$ & $0.6(0.4-1.0)^{*}$ & $196(9.8)$ & $1.3(1.0-1.6)$ \\
\hline Secondary or above & $43(14.0)$ & $1.0(0.6-1.7)$ & $32(3.0)$ & $0.6(0.4-0.9)$ \\
\hline \multicolumn{5}{|c|}{ Waist circumference $(\mathrm{cm})$} \\
\hline Normal & $99(14.7)$ & - & $323(8.6)$ & \\
\hline Abnormal & $60(26.7)$ & $1.5(1.0-2.3)$ & $194(16.5)$ & $1.9(1.5-2.3)$ \\
\hline \multicolumn{5}{|l|}{ SBP (mmHg) } \\
\hline$<120$ & $15(8.4)$ & & $66(5.8)$ & - \\
\hline $120-139$ & $59(13.3)$ & $1.2(0.7-2.3)$ & $252(9.2)$ & $1.4(1.0-1.8)$ \\
\hline $140-159$ & $51(28.2)$ & $2.7(1.4-5.1)$ & $132(17.5)$ & $1.7(1.2-2.4)$ \\
\hline$\geq 160$ & $28(32.6)$ & $2.2(1.0-4.7)$ & $57(21.7)$ & $1.6(1.1-2.5)$ \\
\hline
\end{tabular}

Note: SBP is systolic blood pressure

* Odds ratios adjusted for all variables included in the model.

${ }^{ \pm}$Age is grouped into 17 five-year age bands between 20 and 109 years.

be attributed to rural to urban migration after the $1980 \mathrm{~s}$ oil boom [28]. Although higher than among men, the decreasing rate of obesity among women has been explained by increasing educational levels, declining fertility rates and improved awareness of self-image [28].

Crude estimates indicate that illiterate and less educated individuals are more likely to suffer from diabetes, high blood pressures and high cholesterol. It appears that when all the other factors are considered, education is not independently associated with diabetes. However, when separate analyses were conducted for urban and rural areas, higher educated individuals were less likely to have diabetes particularly in the rural population. This finding has also been demonstrated in Bahrain [29]. It is unclear whether lifestyle characteristics that were not measured in this study, such as exercise and dietary patterns, may be driving the relationship between education and diabetes. Thus, higher educated individuals may be better aware of coronary risk factors and use more effective preventive measures.

Finally, it is important to note that the prevalence of diabetes defined through blood test in Oman is considerably higher than the self-reported prevalence. Less than half of the number of individuals with diabetes as defined by fasting blood glucose reported having diabetes. Indeed the situation is more striking in the urban area of Muscat: among the urban population, $11.1 \%$ of those who declared they did not have diabetes actually did according to blood tests; compared to only $6.2 \%$ among those out- side Muscat. This finding highlights the importance of health education and frequent testing in order to prevent individuals unaware they have diabetes from developing complications associated with the disease [33], particularly in the region of Muscat.

\section{Limitations}

This study is limited by the cross-sectional nature of the data, which does not provide any indication of the direction of effect or causality. This limitation also prevents any measure of temporal changes in prevalence of diabetes and factors associated with diabetes. Longitudinal studies would serve as a complement to the present study to determine causality and directional effect of the factors.

In addition, the blood test used to diagnose diabetes for this study did not differentiate between type 1 and type 2 diabetes. Therefore, the proportion of individuals with diabetes in the lowest age group (3.6\%) is likely suffering from type 1 diabetes. The risk factors associated with the two types of diabetes are different, with a stronger genetic component for type 1 , therefore the significance of the other factors in the model may be underestimated. Indeed in a sensitivity analysis in which we excluded the youngest age groups (age 20-29) from the analysis, the strength of the association between blood pressure and diabetes increased and the relationship between urbanization and diabetes remained unchanged; however the relationship between marital status and diabetes disappeared. 
Finally, because this study uses secondary data collected for the purpose of the National Health Survey, the use of robust standardization methods of data collection, particularly important for measures of blood pressure and anthropomorphic indicators, were not employed. Therefore the potential for minimizing systematic error is limited.

\section{Conclusion}

This study highlights the prevalence of diabetes and associated coronary risk factors in urban Oman. Public health policy should be directed towards this area with a focus on primary prevention of diabetes, hypertension and obesity by lifestyle interventions.

As the relatively young Omani population ages in the future, there will likely be an escalation in the prevalence of diabetes and other chronic diseases. Therefore, it is important to continually monitor the coronary risk factors in Oman, as well as to direct effective public health interventions towards the high risk groups, such as those living in the capital region, individuals with high blood pressure, and obesity.

Chronic disease research in Oman and other countries in the Gulf region would be improved if national surveys collected more detailed information on reported symptoms, dietary patterns, physical exercise, and income level. These data would enable further analysis of chronic diseases and thus help to better inform public health policymakers. Furthermore, a specially designed survey with the objective of determining risk factors of diabetes and cardiovascular disease that incorporates robust standardization methods is needed to confirm the findings of the present study.

At this time it is vital to consider the classification of urban and rural residence in Oman, and other Middle Eastern countries, in order to improve analytical studies as well as the consistency and accuracy of data presented by international organizations.

\section{Competing interests}

The author(s) declare that they have no competing interests.

\section{Authors' contributions}

Siba Al-Moosa conducted the literature review, drafted sections, and assisted with statistical analysis. Sara Allin conducted the statistical analyses, drafted and edited sections. Nadia Jemiai drafted and edited sections, and assisted with statistical analysis. Jawad Al-Lawati provided expertise and oversight throughout the process, and reviewed drafts. Elias Mossialos provided expertise and oversight throughout the research process, and reviewed drafts. All authors read and approved the final manuscript.

\section{Acknowledgements}

We would like to thank Dr Asya Al-Riyami and Dr Mustafa Afifi at the Ministry of Health of Oman for giving us permission to use the data of the National Health Survey 2000 and for providing us with Omani publications. We would also like to thank Mohammed Al-Nomani and Ibrahim Al-Hasani at the Sultan Qaboos University Library for their contribution to our research. We are especially grateful for the advice given by Professor Walter Holland.

\section{References}

I. King H, Aubert RE, Herman WH: Global burden of diabetes, 1995-2025. Diabetes Care 1998, 2 I:|4|4-|43|.

2. Hennis A, Wu S-Y, Nemesure B, Li X, Leske M: Diabetes in a Caribbean population: epidemiological profile and implications. Int J Epidemiol 2002, 3 I:234-239.

3. Hamman RF: Genetic and environmental determinants of noninsulin dependent diabetes mellitus (NIDDM). Diabetes Metab Rev 1993, 8:287-338.

4. King H, Rewers M: WHO Ad Hoc Diabetes Reporting Care Global estimates for prevalence of diabetes mellitus and impaired glucose tolerance in adults. Diabetes Care 1993, 16:157-177.

5. Zimmet P: The pathogenesis and prevention of diabetes in adults: genes, autoimmunity and demography. Diabetes Care 1995, I 8:1050-1064.

6. Abdul-Rahim HF, Abu-Rmeileh NM, Husseini A, Holmboe-Ottesen G, Jervell J, Bjertness E: Obesity and selected co-morbidities in an urban Palestinian population. International Journal of Obesity and Related Metabolic Disorders 200I, 25:I736-I740.

7. Abdul-Rahim HF, Holmboe-Ottesen G, Stene LC, Husseini A, Giacaman R, Jervell J, Bjertness E: Obesity in a rural and an urban Palestinian West Bank population. Int J Obes Relat Metab Disord 2003, 27:140-146.

8. el Mugamer IT, Ali Zayat AS, Hossain MM, Pugh RN: Diabetes, obesity and hypertension in urban and rural people of Bedouin origin in the United Arab Emirates. J Trop Med Hyg 1995, 98:407-4I5.

9. Al-Nozha MM, Al-Maatouq MA, Al-Mazrou YY, Al-Harthi SS, Arafah MR, Khalil MZ, Khan NB, Al-Khadra A, Al-Marzouki K, Nouh MS, Abdullah M, Attas O, Al-Shahid MS, Al-Mobeireek A: Diabetes mellitus in Saudi Arabia. Saudi Medical Journal 2004, 25:1603-1610.

10. Country information: Oman [http://www.who.int/countries/ omn/en/]. 16 December 2004.

II. Al-Riyami A, Afifi M: Distribution and Correlates of Total Impaired Fasting Glucose in Oman. Eastern Mediterranean Health Journal 2003, 9:377-389.

12. Alwan A, Jarrett J: Review of the National Diabetes Programme in Oman. Geneva: World Health Organization 2002.

13. Asfour MG, Lambourne A, Soliman A, Al-Behlani S, Al-Asfoor D, Bold A, Mahtab H, King H: High Prevalence of Diabetes Mellitus and Impaired Glucose Tolerance in the Sultanate of Oman: Results of the I99I National Survey. Diabet Med 1995, I2: I I2-I I 25.

14. Al-Lawati JA, Mohammed AJ, Al-Hinai HQ, Jousilahti P: Prevalence of the Metabolic Syndrome Among Omani Adults. Diabetes Care 2003, 26: 1781-1785.

15. World Health Organization: Definition, diagnosis and classification of diabetes mellitus and its complications. Part I: Diagnosis and classification of diabetes mellitus. Geneva: World Health Organization 1999.

16. The $\mathbf{2 0 0 2}$ Revision and World Urbanization Prospects [http:/ lesa.un.org/unpp/]. 10 October 2005.

17. Information Communications and Technologies at a glance: Oman [http://www.worldbank.org/cgi-bin/send off.cgi?page $=\% 2 F d a t a \% 2 F c o u n t r y d a t a \% 2 F i c t \% 2 F o m n$ ict.pdf]. $\quad 16$ December 2004.

18. Kharoufi M: Urbanization and Urban Research in the Arab World. Discussion Paper Series - No II 1996. 
19. Roberts B: Urban Management in Asia: Issues, Priorities and Opportunities. UMP: Urban Management Programme Regional Office for Asia -Pacific; 2000.

20. Sultanate of Oman Ministry of National Economy: Final results of the census 2003. Muscat: Ministry of National Economy 2003.

21. King H, Minjoot-Preriera G: Diabetes and Non-Communicable Diseases Risk Factor Survey- a field guide. Geneva: World Health Organization; 2000.

22. Sultanate of Oman Ministry of Health: National Health Survey, 2000: Volume I - study of life style risk factors. Muscat: Ministry of Health 2000.

23. De Fronzo RA, Ferrannini E, Keen H, Zimmet P: International Textbook of Diabetes Mellitus, 3rd Edition. Chichester: John Wiley \& Sons, Inc; 2004.

24. Zimmet P: Type 2 (Non-insulin-dependent) diabetes: an epidemiological review. Diabetologia 1982, 22:399-4II.

25. Zimmet P, Taylor R, Ram P, King H, Sloman G, Raper LR, Hunt D: Prevalence of diabetes and impaired glucose tolerance in the biracial (Melanesian and Indian) population of Fiji: a ruralurban comparison. American Journal of Epidemiology 1983, I | 8:673-688.

26. Levitt NS, Katzenellenbogen JM, Bradshaw D, Hoffman MN, Bonnici F: The Prevalence and Identification of Risk factors for NIDDM in Urban Africans in Cape Town, South Africa. Diabetes Care 1993, I 6:601-607.

27. Al-Lawati JA, Al Riyami AM, Mohammed AJ, Jousilahti P: Increasing prevalence of diabetes mellitus in Oman. Diabet Med 2002, 19:954-957.

28. Al-Lawati J, Jousilahti P: Prevalence and I0-year Secular Trend of Obesity in Oman. Saudi Medical Journal 2004, 25:346-35I.

29. Al-Mahroos F, Al-Roomi K, McKeigue PM: Relation of high blood pressure to glucose intolerance, plasma lipids and educational status in an Arabian Gulf population. Int J Epidemiol 2000 29:7I-76.

30. Haffner SM: The prediabetic problem: development of noninsulin-dependent diabetes mellitus and related abnormalities. Journal of Diabetes Complication 1997, I I:69-76.

31. Njolstad I, Arnesen E, Lund-Larsen PG: Sex differences in risk factors for clinical diabetes mellitus in a general population: a I 2-year follow-up of the Finnmark Study. American Journal of Epidemiology 1998, 147:49-58.

32. Gress TW: Hypertension and antihypertensive therapy as risk factors for type 2 diabetes mellitus. N Engl J Med 2000, 342:905-912.

33. Al-Riyami A, Afifi M: Accuracy of self-reporting of diabetes mellitus and hypertension and its determinants among Omani adults. Saudi Medical Journal 2003, 24:1025-1026.

\section{Publish with Bio Med Central and every scientist can read your work free of charge}

"BioMed Central will be the most significant development for disseminating the results of biomedical research in our lifetime. "

Sir Paul Nurse, Cancer Research UK

Your research papers will be:

- available free of charge to the entire biomedical community

- peer reviewed and published immediately upon acceptance

- cited in PubMed and archived on PubMed Central

- yours - you keep the copyright
BioMedcentral 